\title{
INFLUENCE OF THE DISTANCE OF THE CURING LIGHT SOURCE AND COMPOSITE SHADE ON HARDNESS OF TWO COMPOSITES
}

\author{
Thaís THOMÉ ${ }^{1}$, Washington STEAGALL Jr. ${ }^{1}$, Arlene TACHIBANA ${ }^{1}$, Sheila Regina Maia BRAGA ${ }^{1}$, Miriam Lacalle TURBINO²
}

1- DDS, MSc, Graduate student - Department of Dentistry of Dental School - University of São Paulo - FOUSP - São Paulo - Brazil.

2- DDS, MSc, PhD -Full Professor - Department of Dentistry of Dental School - University of São Paulo - FOUSP - São Paulo - Brazil.

Corresponding address: Profa. Dra. Miriam Lacalle Turbino - Department of Dentistry, Dental School - Av. Lineu Prestes, 2227 - $05508-$ 900 - University of São Paulo, São Paulo, SP, Brazil - Phone: 551130917839 - Fax: 551130917839 - e-mail: miturbin@usp.br

Received: March 09, 2007 - Modification: June 13, 2007 - Accepted: July 10, 2007

\begin{abstract}
$T_{\text {his }}$ his study evaluated the influence of curing tip distance, shade and filler particle size on Vickers microhardness (VHN) of composite resins. Two composites were tested: Filtek Z250 microhybrid (3M ESPE; shades A1 and A3.5) and Filtek Supreme nanofilled (3M ESPE; shades A1B and A3.5B). For each resin, 42 specimens (5 mm in diameter and $2 \mathrm{~mm}$ height) were prepared being 21 for each shade. The specimens were exposed using a 20-second exposure to a quartz-tungsten-halogen light source with an irradiance of approximately $560 \mathrm{~mW} / \mathrm{cm}^{2}$, at the following distances: $0 \mathrm{~mm}$ (surface contact), $6 \mathrm{~mm}$ and $12 \mathrm{~mm}$ from composite surface. Effectiveness of cure of different resins, shades and curing distances was determined by measuring the top and bottom hardness (VHN) of specimens using a digital microhardness tester (load: 50 g; dwell time: 45 seconds) 24 hours following curing. The hardness ratio was calculated by dividing VHN of the bottom surface by VHN of top surface. Three-way ANOVA and Tukey's post-hoc test $(\mathrm{p}<0.05)$ revealed statistically significant differences for all analyzed factors. As for top hardness, as microhardness ratio (bottom/top), the factors shade, distance and composite filler particle size exerted influence on resin curing. Lighter shade composites (A1 and A1B) showed higher hardness values. At 6 and 12 mm curing tip distances, hardness was lower when compared to $0 \mathrm{~mm}$. The microhybrid composite resin presented higheer hardness, being its microhardness ratio satisfactory only at $0 \mathrm{~mm}$ for both shades and at $6 \mathrm{~mm}$ for the lighter shade. The nanofilled composite resin did not present satisfactory microhardness at the bottom while the microhybrid composite resin had higher hardness than the nanofilled. Composite’s curing tip distance and shade can influence hardness.
\end{abstract}

Uniterms: Hardness tests; Composite resins; Shades.

\section{INTRODUCTION}

The clinical success of composite resins is directly related to the polymerization process. A satisfactory polymerization of a composite resin relies on some variables, such as hue, translucency, filler particle size, time of light exposure, increment thickness, light intensity and light source distance ${ }^{3,14,16,17,19,20,23,25}$.

Research has shown that the an adequate polymerization demands light intensities greater than $280 \mathrm{~mW} / \mathrm{cm}^{2},{ }^{21}$ increment thickness of $2 \mathrm{~mm}$ or less $\mathrm{s}^{5,14,19}$, and a distance between the light source and the composite's surface no greater than $6 \mathrm{~mm}^{5}$. The light intensity diminishes as the tip of the source light moves away from the composite's surface. Ideally, the light-curing tip unit should be in direct contact with the restoration's surface ${ }^{4}$. However, sometimes cavity design does not allow the polymerization within this distance..$^{18}$ Actually, distances of more than $8 \mathrm{~mm}$ between light source and the bottom of the proximal cavity have been demonstrated ${ }^{11}$. Clinical factors such as the accessibility of the light source, the direction of the light, cavity depth and intervening tooth tissue may limit depth of cure $^{23}$.

Studies had demonstrated that the composite resin shade can also influence the polymerization process, attenuating the energy passing through the specimen's thickness, diminishing the light transmission, which can be verified, with a substantially lower hardness values ${ }^{5,25}$. Resins with lighter shades, belonging to the same system, show higher hardness values in comparison to darker shades ${ }^{10}$. Darker shade resins require more light exposure time and thinner increments, in order to achieve higher hardness values ${ }^{16,19}$. Sometimes, not only the shade, but the resin's relative translucency can influence in the light transmission through the composite's thickness ${ }^{12}$.

The filler particles can also absorb light, when they have 
heavy metals in their composition, generally used to provide radiopacity ${ }^{24}$.

This study evaluated the influence of filler size, shade and light source distance on the degree of polymerization and superficial microhardness of composite resins, by determining their Vickers microhardness.

\section{MATERIALS AND METHODS}

Two types of composite resins were tested: (1) Filtek Z250 microhybrid resin (3M, Dental Products Division, St. Paul, MN, USA; shades A1 and A3.5) and (2) Filtek Supreme nanofilled resin (3M, Dental Products Division, St. Paul, MN, USA; A1B and A3.5B shades) (Table 1).

Twenty-one specimens were made for each composite's shade, being 7 specimens for each light curing distance, totaling 84 specimens. The specimens were obtained from a split cylindrical black Teflon mold, with $5 \mathrm{~mm}$ of inner diameter and $2 \mathrm{~mm}$ height, united by a metal ring. This mold was covered with an experimental setup, containing a black cardboard paper, a microscope slide and a Mylar matrix.

The resins were inserted into the mold, in a single increment, with slight excess and covered by another transparent matrix strip. A second microscope slide was used to adapt the matrix to the margins of the mold thus creating a flat surface in both specimen surfaces and pressing the excess material over the brim of the mold. This microscope slide was removed before polymerization.

The specimens were light-cured for 20 seconds with the following distances: $0 \mathrm{~mm}$ (surface contact), $6 \mathrm{~mm}$ and 12 mm from composite surface, using a quartz-tungsten-halogen light source (XL 3000/3M) with an irradiance of approximately $560 \mathrm{~mW} / \mathrm{cm}^{2}$. The distances were standardized using plastic rings that acted as spacers with $6 \mathrm{~mm}$ height. For $12 \mathrm{~mm}$ distance, 2 rings were used. Excess material was removed after irradiation.

The specimens were stored dry at $37^{\circ} \mathrm{C}$ for 24 hours in the dark. The Vickers Hardness Numbers (VHN) were measured using a microhardness tester HMV-2000 (Shimadzu Corporation, Japan) in an automatic procedure with load of
$50 \mathrm{~g}$ applied for 45 seconds. On each specimen five indentations were made on the irradiated and opposite surfaces for each specimen, totaling 10 indentations for each specimen. The data referring to top surface from each resinbased composite were compared and the microhardness ratio was computed by dividing VHN of the bottom surface by VHN of the top surface. The values accepted as satisfactory for the microhardness ratio were at least equal or greater than $80 \% .{ }^{25}$ Data were analyzed by three-way ANOVA with curing tip distance, shade and filler size serving as the factors. Differences between composite resins and shades were evaluated for each curing tip distance separately and viceversa, using Tukey's test. The significance level was set at $5 \%$.

\section{RESULTS}

There were statistically significant differences for all analyzed factors. Regarding superficial hardness, as in microhardness ratio, the factors shade, distance and composite resin type exerted influence.

The composites with lighter shades (A1 and A1B) showed, in general, higher Vickers microhardness values, than the corresponding darker shades (A3.5 and A3.5B). For microhardness values, that represent the depth of polymerization, in this case at $2 \mathrm{~mm}$, values greater than $80 \%$, were verified only for the microhybrid composite, for both shades at $0 \mathrm{~mm}$ and for the lighter shade (A1) at $6 \mathrm{~mm}$. The nanofilled resin did not show, for microhardness ratio, values greater than $80 \%$ for any distance and shade tested. The hardness ratio (VHN of the bottom surface by VHN of top surface) for each resin, shade and distance tested are displayed on Table 2. The highest value for the bottom/top microhardness (VHN) was 87.26\% for the microhybrid resin with A3.5 shade at $0 \mathrm{~mm}$, and the lowest value was $50.20 \%$ for the nanofilled resin with A3.5B shade at $12 \mathrm{~mm}(\mathrm{p}<0.05)$.

For the irradiated surface, the highest value of microhardness was 98.26 VHN (Vickers Hardness Number) for the microhybrid resin with $\mathrm{A} 1$ shade at $0 \mathrm{~mm}$ and the lowest value was 61.97 VHN for the nanofilled resin with

TABLE 1- Tested materials and their technical profiles

\begin{tabular}{|c|c|c|c|c|c|c|c|}
\hline Material & Manufacturer & Shade & Resin & $\begin{array}{l}\text { Cure } \\
\text { Time }\end{array}$ & Filler & $\begin{array}{l}\text { Filler Size } \\
\qquad(\mu \mathrm{m})\end{array}$ & $\begin{array}{l}\text { Filler content } \\
\text { (\% by volume) }\end{array}$ \\
\hline $\begin{array}{l}\text { Filtek } \\
\text { Z-250 }\end{array}$ & $\begin{array}{c}\text { 3M (St. Paul, } \\
\text { MN, USA) }\end{array}$ & $\begin{array}{c}\text { A1 and } \\
\text { A3.5 }\end{array}$ & $\begin{array}{c}\text { BisGMA } \\
\text { UDMA } \\
\text { BisEMA }\end{array}$ & $20 \mathrm{~s}$ & $\begin{array}{l}\text { Zirconia/ } \\
\text { Silica }\end{array}$ & $0.1-3.5$ & 60 \\
\hline $\begin{array}{c}\text { Filtek } \\
\text { Supreme }\end{array}$ & $\begin{array}{c}\text { 3M (St. Paul, } \\
\text { MN, USA) }\end{array}$ & $\begin{array}{c}A 1 B \text { and } \\
\text { A3,5B }\end{array}$ & $\begin{array}{c}\text { BisGMA } \\
\text { UDMA } \\
\text { BisEMA } \\
\text { TEGDMA }\end{array}$ & $20 \mathrm{~s}$ & $\begin{array}{c}\text { Zirconia/ } \\
\text { Silica }\end{array}$ & $\begin{array}{c}0.005-0.02 \\
\text { nanofiller/ } \\
0.6-1.4 \\
\text { cluster }\end{array}$ & $78.5 \%$ \\
\hline
\end{tabular}


TABLE 2- Microhardness ratio (\%) for each distance, resin and shade

\begin{tabular}{|c|c|c|c|c|c|c|}
\hline & \multicolumn{2}{|c|}{$0 \mathrm{~mm}$} & \multicolumn{2}{|c|}{$6 \mathrm{~mm}$} & \multicolumn{2}{|c|}{$12 \mathrm{~mm}$} \\
\hline & $\mathrm{A} 1$ & A3.5 & $\mathrm{A} 1$ & A3.5 & $\mathrm{A} 1$ & A3.5 \\
\hline Filtek Z-250 & $86.60(4.8)^{a^{*}}$ & $87.26(3.53)^{a}$ & $85.93(3.92)^{a}$ & $76.74(4.85)^{b}$ & $76.09(7.33)^{\mathrm{b}}$ & $67.89(4.90)^{\mathrm{c}}$ \\
\hline & A1B & A3.5B & A1B & A3.5B & A1B & A3.5B \\
\hline Filtek Supreme & $79.77(3.48)^{a . b}$ & $76.86(3.87)^{\mathrm{b}}$ & $71.39(5.64)^{\mathrm{b.c}}$ & $59.29(2.98)^{d}$ & $62.76(1.63)^{\mathrm{c.d}}$ & $50.20(1.75)^{\mathrm{e}}$ \\
\hline
\end{tabular}

*Data are presented as mean (standard deviation), $n=7$. Groups with the same superscript letters are not significantly different (Tukey's post-hoc multiple comparison test; $p>0.05$ ).

TABLE 3- Top surface Vickers Hardness Number (VHN) for each distance, resin and shade

\begin{tabular}{|c|c|c|c|c|c|c|}
\hline & \multicolumn{2}{|c|}{$0 \mathrm{~mm}$} & \multicolumn{2}{|c|}{$6 \mathrm{~mm}$} & \multicolumn{2}{|c|}{$12 \mathrm{~mm}$} \\
\hline & A1 & A3.5 & A1 & A3.5 & A1 & A3.5 \\
\hline Filtek Z-250 & $98.36(10.21)^{a^{*}}$ & $90.55(2.53)^{\mathrm{b}}$ & $81.63(3.87)^{c}$ & $76.84(4.07)^{\text {c.d }}$ & $68.27(3.11)^{\mathrm{e}}$ & $71.17(1.62)^{\text {d.e.f }}$ \\
\hline & A1B & A3.5B & A1B & A3.5B & A1B & A3.5B \\
\hline Filtek Supreme & $83.99(1.54)^{b . c}$ & $76.29(3.24)^{c . f}$ & $79.92(3.28)^{c . d}$ & $74.27(2.89)^{\text {d.e.f }}$ & $67.31(0.95)^{\mathrm{e}}$ & $61.97(1.55)^{\mathrm{e}}$ \\
\hline
\end{tabular}

*Data are presented as mean (standard deviation), $n=7$. Groups with the same superscript letters are not significantly different (Tukey post hoc multiple comparison test; $p>0.05$ ).

\section{Microhardness Ratio}

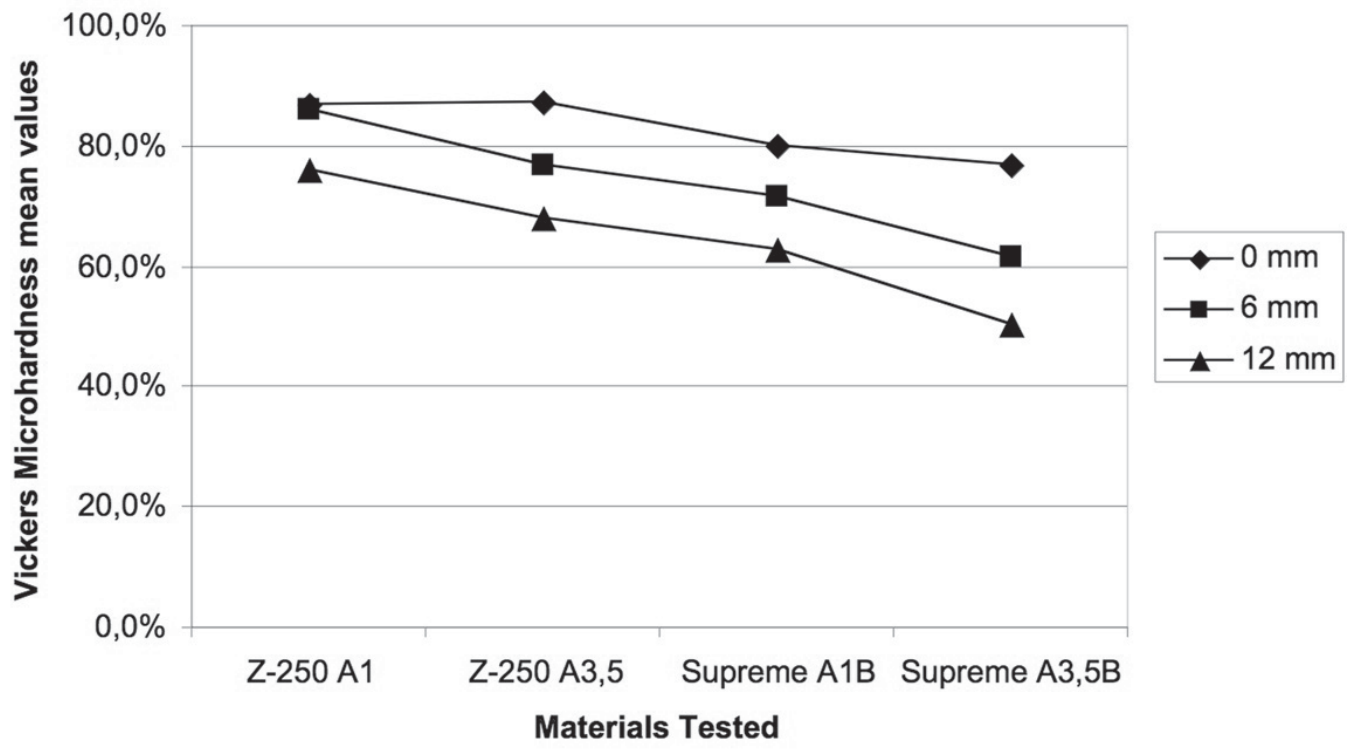

FIGURE 1- Microhardness ratio of the tested materials. The values accepted as satisfactory were at least equal or greater than $80 \%$

A3.5B shade at $12 \mathrm{~mm}(\mathrm{p}<0.05)$. The values for the irradiated surface in VHN for each resin, shade and distance tested are displayed on Table 3.

The means for the top surface hardness and microhardness ratio showed a decrease in their values as the distance between the light source tip and the irradiated surface increased. For both composites tested the highest values were recorded at $0 \mathrm{~mm}$ (surface contact) and the 
Top Surface Microhardness

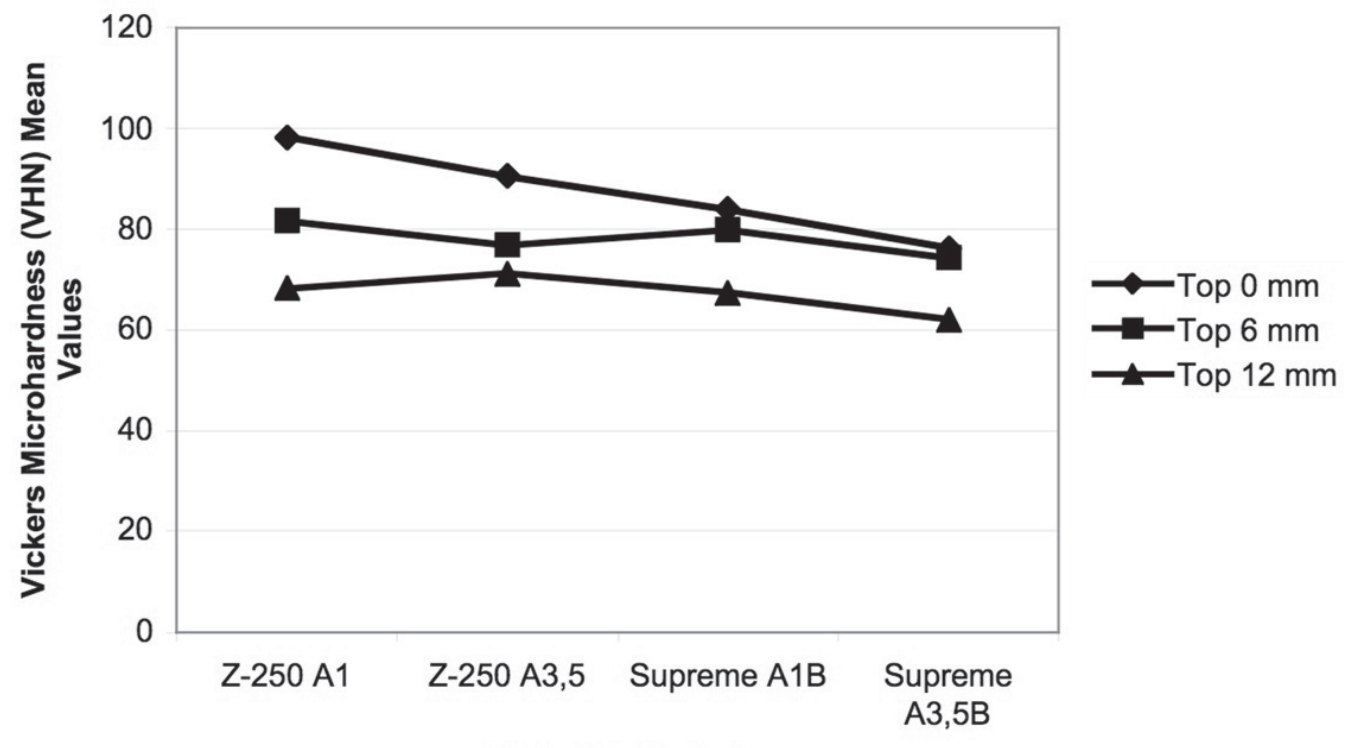

Materials Tested

FIGURE 2- Top surface microhardness for the tested materials

lowest values at $12 \mathrm{~mm}$

\section{DISCUSSION}

The experimental results support the theory that the shade, particle size and distance of the light source influence the superficial VHN and microhardness ratio of composite resins.

Hardness test has been the most popular method for investigating factors that influence the degree of conversion of composite resins ${ }^{23}$. It has been reported that this test provides an estimation of the degree of conversion of a composite resin ${ }^{1,8,9}$. However hardness values cannot be used to directly compare conversion of different composites, the bottom/top ratios for both hardness and degree of conversion, evaluated using attenuated total reflectance in a Fourier transform infrared (FTIR) spectrometer, resulted in a linear relationship independent of filler size or loading ${ }^{2}$.

When tested under the same conditions, darker shades showed lower hardness ratio and superficial hardness when compared to lighter shades. These results are in agreement with the statement that the pigments used to give darker tonality to composite resins can attenuate the light transmission through the resin lowering the polymerization $^{5,10,14,23,25}$. Darker composite resins have a tendency to absorb light and, because of that, they demand more time of light exposure and increments as thick as 1 mm. ${ }^{19}$

Light absorption can also be explained by the changing in the refractive index of the composite as the polymerization is taking place through the specimen's thickness. Chen, et al. ${ }^{6}$ showed that the composite resins have a dynamic behavior as the monomers are converted into polymer chains because of the changing of the refractive index of the monomers while they are being photoactivated and converted into polymers. Inokoshi et al. ${ }^{13}$ showed that the greater the difference between the refractive indexes between the organic phase and the filler phase, the greater the opacity, due the multiple reflections and refractions in the organic phase and filler phase interfaces.

The filler can also attenuate light when heavy metals are present in its constitution. ${ }^{24}$ Both resins used in this study have filler with $\mathrm{ZiO}_{2}$. These fillers are used to give radiopacity to these materials.

The major influence of the filler on light propagation through the restoration thickness is due to light scattering. The scattering is wavelength and filler particle diameter dependent principally with composites with size particle ranging between 0.1 to $1.0 \mu \mathrm{m}^{5,14,15}$. In the case of composite resins, the most important wavelength involved is $470 \mathrm{~nm}$, the maximum absorption peak of camphorquinone. The majority of the light-sensitive materials used in dentistry have camphorquinone as initiation agent. Exposed to the correct wavelength, the camphorquinone molecule is raised to the triplet state and in this condition can react with a reducing agent to form an epiplex. This epiplex can then break down to form free radicals and initiate polymerization $^{21,22}$. The scattering is more efficient, resulting in greater light attenuation when the filler particles have half of the diameter of the incident wavelength; and this diminishes as the diameter increases. When particles are getting larger than the incident wavelength, the scattering occurs by light reflection over the particle's surface, in this case propagating more light ${ }^{22}$. Nanofilled, microhybrid and some hybrid composites have filler particles with this size range, and some attenuation by scattering is always expected when this type of resin-based composites are used, although 
the relative contribution of filler size is not so significant in depth of cure as increment thickness and exposure time ${ }^{5}$.

Comparing both resins, it was observed that lower values for the microhardness ratio are verified for the nanofilled resin for both shades (Table 2). There was greater light attenuation for these composite. This attenuation can be explained by the light absorption, the greater amount of pigments and the greater percentage of filler by weight when compared to the microhybrid composite (Table 1 ). In addition, the nanofilled composite had a complex filler system and no information was available about the range of particle diameters that could be found on its composition. Despite the fact that the microhybrid resin was a "universal" type composite and the nanofilled resin was a "body" type composite, both materials were tested under the same conditions, and both had similar directions from their manufacturers, regarding specimen's thickness and light time exposure. Although the nanofilled resin was launched in the market with the intention of offering enhanced polymerization depth, this was not observed by us experimentally.

The light source distance in the polymerization of the composite resins had a negative influence with the increase of the distance with all tested resins. The distance of contact ( $0 \mathrm{~mm}$ ), when the tip of the light source was in contact with the specimen's surface, had always higher superficial microhardness values and microhardness ratio in all tested specimens (Figures 1 and 2). Light intensity diminished as the tip of the light source moved away from the restoration's surface. The clinical distance recommended between the tip of the light source and the resin surface is $1 \mathrm{~mm}$, but this is not always possible, for example, in cases of deep Class II gingival walls of proximal boxes. Here, the distance between the light source and the first increment (deep in the preparation) will be greater because of the interference of the oclusal surface. In these clinical situations, the clinician will have to use other resources that allow the adequate polymerization of these increments, such as transparent matrix strips, thinner increments, longer time of light exposure and greater light intensities ${ }^{18}$. El-Mowafy, et al. ${ }^{7}$ observed that LED units performed as well as the quartz-tungstenhalogen sources in polymerization of composites in class II cavities. However, longer curing cycles (60 seconds) had significant effects on relative hardness values.

\section{CONCLUSIONS}

Under the tested conditions, it was observed that regarding microhardness, longer exposure times and thinner increments (about $1 \mathrm{~mm}$ ) should be used when resins with darker shades and/or small filler particles (similar to the wavelength used) are chosen for a restorative treatment. The distance between the tip of the light source and the restoration surface should be as close as possible, and when this proximity was not possible, the clinician should use other resources that allow the adequate polymerization of the material.

\section{REFERENCES}

1- Asmussen E. Restorative resins: Hardness and strength versus quantity of remaining double bonds. Scand J Dent Res. 1982;90:4849 .

2- Bouschlicher MR, Rueggeberg FA, Wilson BM. Correlation of bottom-to-top surface microhardness and conversion ratios for a variety of resin composite compositions. Oper Dent. 2004;29:698704.

3- Burgess JO, Walker R, Davidson JM. Posterior resin-based composite: review of the literature. Pediatr Dent 2002;24:465-79.

4- Caldas DBM, Almeida JB, Correr-Sobrinho L, Sinhoreti MAC, Consani S. Influence of curing tip distance on resin composite Knoop Hardness Number, using three different light curing units. Oper Dent. 2003;28:315-20.

5- Caughman WF, Rueggeberg FA, Curtis JW Jr. Clinical guidelines for photocuring restorative resins. J Am Dent Assoc. 1995;126:1280-6.

6- Chen YC, Ferracane JL, Prahl SA. A pilot study of a simple photon migration model for predicting depth of cure in dental composite. Dent Mater. 2005;21:1075-86.

7- El-Mowafy O, El-Badrawy W, Wasef M, Omar H, Kermanshahi S. Efficacy of new LED light-curing units in hardening of class II composite restorations. J Can Dent Assoc. 2007;73:253-8.

8- Ferracane JL. Correlation between hardness and degree of conversion during the setting reaction of unfilled dental restorative resins Dent Mater. 1985;1:11-4.

9- Ferracane JL, Greener EH. The effect of resin formulation on the degree of conversion and mechanical properties of dental restorative resins. J Biomed Mater Res. 1986;20:121-31.

10- Friedman J, Hassan R. Comparison study of visible curing lights and hardness of light-cured restorative materials. J Prosthet Dent. 1984;52:504-6.

11- Hansen EK, Asmussen E. Visible-light curing units: Correlation between depth of cure and distance between depth of cure and distance between exit window and resin surface Acta Odontol Scand. 1997;55:162-6.

12- Ikeda T, Murata Y, Sano H. Translucency of opaque-shade resin composites. Am J Dent. 2004;17:127-30.

13- Inokoshi S, Burrow MF, Kataumi M, Yamada T, Takatsu T. Opacity changes of tooth-colored restorative materials. Oper Dent. 1996;21:73-80.

14- Kanca J. The effect of thickness and shade on the polymerization of light-activated posterior composite resins. Quintessence Int. 1986;17:809-11.

15- Leonard DL, Charlton DG, Roberts HR, Hilton TJ, Zionic A. Determination of the minimum irradiance required for adequate polymerization of a hybrid and a microfill composite Oper Dent. 2001;26:176-80.

16- Mandarino F, Angelis Porto CL, Fontana UF, Cândido MSM, Oliveira Júnior OB. Efeito da tonalidade de cor sobre a profundidade de polimerização das resinas compostas fotopolimerizáveis. Rev Bras Odontol. 1992;49:38-41.

17- McCabe JF, Carrick TE. Output from visible-light activation units and depth of cure of light-activated composites. J Dent Res. 1989;68:1534-9. 
18- Pires JAF, Cvitzo E, Denehy GE, Swift Jr. E. Effects of curing tip distance on light intensity and composite resin microhardness. Quintessence Int. 1993;24:517-21.

19- Prince RB, Dérand T, Loney RW, Andreou P. Effect of light source and specimen thickness on the surface hardness of resin composite. Am J Dent 2002;15:47-53.

20- Prince RBT, Felix CA, Andreou P. Effects of resin composite composition and irradiation distance on the performance of curing lights. Biomaterials. 2004;25:4465-77.

21- Rueggeberg FA, Caughman WF, Curtis JWJr. Effect of light intensity and exposure duration on cure of resin composites. Oper Dent. 1994;19:26-32.

22- Ruyter IE, ØYSÆD H. Conversion in different depths of ultraviolet and visible light activated composite materials. Acta Odontol Scand. 1982;40:179-92.

23- Shortall AC, Wilson HJ, Harrington E. Depth of cure of radiationactivated composite restoratives - Influence of shade and opacity. J Oral Rehabil. 1995;22:337-42.

24- Taira M, Okasaki M, Takahashi J. Studies on optical properties of two commercial visible-light-cured composite resins by diffuse reflectance measurements. J Oral Rehabil. 1999;26:329-37.

25- Watts DC, Amer O. Combe EC. Characteristics of visible-lightactivated composite systems. Br Dent J. 1984;156:209-15. 